\title{
Anti-apoptotic effects of osteopontin through the up-regulation of Mcl-1 in gastrointestinal stromal
} tumors

\author{
Kai-Hsi Hsu' ${ }^{1,2,3}$, Hung-Wen Tsai, ${ }^{3,4}$, Pin-Wen Lin², Yun-Shang Hsu', Pei-Jung Lü and Yan-Shen Shan²,3*
}

\begin{abstract}
Background: Osteopontin (OPN) is a secreted phosphoprotein expressed by neoplastic cells involved in the malignant potential and aggressive phenotypes of human malignancies, including gastrointestinal stromal tumors (GISTs). Our previous study showed that OPN can promote tumor cell proliferation in GISTs. In this series, we further aim to investigate the effect of OPN on apoptosis in GISTs.

Methods: The expression of apoptotic and anti-apoptotic proteins in response to OPN was evaluated. In vitro effects of OPN against apoptosis in GIST were also assessed. GIST specimens were also used for analyzing protein expression of specific apoptosis-related molecules and their clinicopathologic significance.

Results: Up-regulation of $\beta$-catenin and anti-apoptotic proteins $\mathrm{Mcl}-1$ with concomitant suppression of apoptotic proteins in response to OPN was noted. A significant anti-apoptotic effect of OPN on imatinib-induced apoptosis was identified. Furthermore, Mcl-1 overexpression was significantly associated with OPN and $\beta$-catenin expression in tumor tissues, as well as worse survival clinically.

Conclusions: Our study identifies anti-apoptotic effects of OPN that, through $\beta$-catenin-mediated Mcl-1 up-regulation, significantly antagonized imatinib-induced apoptosis in GISTs. These results provide a potential rationale for therapeutic strategies targeting both OPN and Mcl-1 of the same anti-apoptotic signaling pathway, which may account for resistance to imatinib in GISTs.
\end{abstract}

Keywords: Apoptosis, Gastrointestinal stromal tumor, Mcl-1, Osteopontin

\section{Background}

Gastrointestinal stromal tumors (GISTs), the most common type of gastrointestinal tract mesenchymal tumor, originate from the interstitial cells of Cajal in the myenteric plexus of the digestive tract, with the stomach being the most common tumor location. The pathogenesis of GIST is gain-of-function mutations of the protooncogene KIT in the majority, or platelet-derived growth factor receptor $\alpha$ (PDGFRA), with resultant encoding of related proteins, KIT, or PDGFRA receptors that contain ligand-independent kinase activity, leading to persistent and uncontrolled cell proliferation as well as resistance

\footnotetext{
* Correspondence: ysshan@mail.ncku.edu.tw

${ }^{2}$ Department of Surgery, National Cheng Kung University, College of Medicine, Tainan 70428, Taiwan

${ }^{3}$ Institute of Clinical Medicine, National Cheng Kung University, College of Medicine, 138, Sheng-Li Road, Tainan 70428, Taiwan

Full list of author information is available at the end of the article
}

to apoptosis [1,2]. It has also recently been proposed that ETV1, one of the ETS family transcription factors, cooperates with KIT in the tumorigenesis of GIST [3].

Surgery remains the standard and curative treatment of choice for patients with a resectable GIST. Target therapy using imatinib mesylate, a KIT receptor inhibitor, is indicated in those with advanced or unresectable GIST, or in high-risk patients after surgery as an adjuvant therapy $[4,5]$. However, acquired or secondary resistance to imatinib may occur in GIST patients under imatinib treatment for disease recurrence or progression $[6,7]$. It is therefore important to identify the mechanisms underlying imatinib-resistance so that therapeutic interventions can be developed and applied to this particular GIST patient group.

Osteopontin (OPN), initially termed Eta-1, standing for early $\mathrm{T}$ cell activation gene 1 , or spp 1 , abbreviated 
from secreted phosphoprotein 1, was originally identified as a secreted protein from transformed mammalian cells $[8,9]$. OPN is currently known as a multifunctional secreted glycophosphoprotein expressed in many cell and tissue types and has been found to participate in numerous cellular functions of both physiologic and pathologic significance $[10,11]$. OPN, being frequently overexpressed in miscellaneous tumor cell types, plays important roles in their malignant potential and aggressiveness, including tumor growth, invasion, metastasis, survival, angiogenesis, and tumorigenesis [12-14].

The clinical significance of OPN as a biomarker for poor prognosis has been reported in many human malignancies, including GISTs [12,15-18]. In addition to the clinicopathologic significance of OPN that independently predicts poor clinical outcomes in GIST, we also identified that OPN, upon its interaction with CD44, a type I transmembrane receptor that recognizes OPN as one of its important ligands, contributes to tumor cell proliferation in GIST cell lines $[9,19]$. These data add to evidence supporting the role of OPN as well as its interaction with CD44 in the functional regulation of cancer cells $[17,18]$.

In addition to increased proliferation, anti-apoptosis or suppression of apoptosis, is a common strategy tumor cells use for tumor progression and drug-resistance. Based on the significance of OPN in the antagonistic regulation of apoptosis noted in normal cells as well as in malignant cells [20-24], pharmaceutical inhibition of OPN as the target for induction of apoptosis has been proposed in several human malignancies experimentally and clinically $[25,26]$. Since tumor cell proliferation and apoptosis are closely related and usually coexisting hallmark features characteristic of cancer cells, including GIST, and since we have identified the effect of OPN on promoting tumor proliferation in GIST, we then further hypothesize that OPN may also play a role in the regulation of apoptosis in GIST. This study therefore aims to investigate the effects of OPN in relation to apoptosis and anti-apoptosis in GIST.

\section{Methods}

\section{Cell lines and cell culture}

GIST cell lines, including imatinib-sensitive GIST882, and imatinib-resistant GIST48B and GIST62, were kindly provided by Dr. Chen from the National Health Research Institute (Tainan, Taiwan) and were maintained in RPMI media (Invitrogen) with 10\% fetal bovine serum (Sigma) in a humidified atmosphere with $5 \% \mathrm{CO}_{2}$ and $95 \%$ air at $37^{\circ} \mathrm{C}$.

\section{Construction of shRNA and transient transfection}

The shRNA against OPN was conducted by delivery of shRNA plasmid DNA into cells using the lipofectamine method with a ratio of $5 \mu \mathrm{g}$ DNA per $30 \mu \mathrm{L}$ lipofectamine
(Qiagen, Hilden, Germany). Cells transfected with plasmid of luciferase gene serve as the vector control. After DNA transfection, cells are grown in regular medium for 48 hours and transfection efficacy is evaluated by luciferase bioactivity.

\section{Patients and tissue samples}

Between January 2002 and January 2012, 31 patients undergoing surgery for primary GIST at the National Cheng Kung University Hospital were included for evaluation. The diagnosis of GIST was confirmed by positive KIT immunohistochemical staining of tumor specimens. The surgical principle for each patient was to achieve complete tumor excision with microscopically negative margins. Patients received regular follow-up at the outpatient department for abdominal ultrasonography or CT every three months. No patients received adjuvant or neoadjuvant therapy. Written informed consent was obtained from all patients and the institute review board of the National Cheng Kung University Hospital approved this study.

\section{Western blotting analysis}

GIST cell lines GIST882, GIST48B, and GIST62 as well as tumor tissues preserved in liquid nitrogen $\left(-80^{\circ} \mathrm{C}\right)$ from 31 GIST patients were used for western blotting analysis. Pair-matched normal tissues from 16 of these 31 patients were also used for comparison. Tumor specimens were lysed with PBS/TDS lysis buffer as described previously $[17,18]$. The tissue lysate was centrifuged at $15,000 \times g$ for removal of insoluble cellular materials (Beckman Coulter). Protein concentrations were measured by the Pierce BCA protein assay (Pierce). Equal amounts of protein were subjected to electrophoresis on $10 \%$ sodium dodecyl sulfate-polyacrylamide gel electrophoresis gels (Amersham Pharmacia Biotech) and then transferred to PVDF filters (Perkin-Elmer). GIST882 cell lysate samples of $30 \mu \mathrm{g}$ were used for the same procedures. The filters were then blocked in PBS containing $10 \%$ skim milk (BD) for 60 minutes and subsequently incubated with a 1:500 dilution of rabbit polyclonal antiCD44 antibody (Abcam; ab65829), a 1:50 dilution of mouse monoclonal anti- $\beta$-catenin antibody (Santa Cruz; sc7963), a 1:1,000 dilution of rabbit polyclonal anti-Mcl-1 antibody (Santa Cruz; sc-819), rabbit monoclonal antiBak antibody (Abcam; ab32371), rabbit polyclonal antiXIAP antibody (Abcam; ab2541), and a 1:10,000 dilution of mouse monoclonal anti- $\beta$-actin antibody (Sigma; A1978) in PBS containing 0.03\% Tween 20 overnight. The PDVF filters were then washed three times for 5 minutes with PBS containing 0.3\% Tween 20 (Merck) and then incubated for 60 minutes with horseradish peroxidaseconjugated anti-rabbit IgG antibody (Amersham) for anti-CD44cyto antibody, anti-Mcl-1 antibody, anti-Bak 
antibody, anti-XIAP antibody, and with horseradish peroxidase-conjugated anti-mouse IgG (GE) for anti$\beta$-catenin antibody and anti- $\beta$-actin antibody. Detection of secondary antibodies was done by using an enhanced chemiluminescence system (Amersham). We used the muscle tissue of the paired-match normal tissue as the normal control of beta-catenin in Western blot analysis. The positive control of the western blot analysis of Mcl-1 in GIST was the HEK293 cell lysate.

\section{Terminal deoxynucleotidyl transferase-mediated dUTP nick end labeling (TUNEL) assay}

Equal amounts of GIST882 cells were deposited on glass slides for fixation. TUNEL was performed using TACS-2 TdT-Fluor In Situ Apoptosis Detection Kit (Trevigen) according to the manufacturer's instructions. The apoptotic index (per $\times 200$ microscopic field) was calculated as the number of apoptotic cells $\times 200$ per total number of cells under a fluorescence microscope (Olympus, Tokyo, Japan).

\section{Immunohistochemistry}

Formalin-fixed and paraffin-embedded blocks from 31 GIST tumor specimens were prepared and treated as previously described [27]. The same protocol was used for detection of immunoreactivity, counterstaining, and selection of positive and negative controls. The primary antibodies used were mouse monoclonal anti-OPN antibody (Santa Cruz; sc21742) at 1:500 dilution and rabbit polyclonal anti-Mcl-1 antibody (Santa Cruz; sc-819) at 1:1,000 dilution. The secondary antibodies and avidinbiotin-complex were then applied. Semiquantitative evaluation of the immunohistochemical staining was done by two investigators blinded to the clinical information separately. The grading of OPN expression was categorized according to the same criteria as described previously [18].

\section{Statistical analysis}

Comparison between the two groups was done by independent sample $t$-test for continuous variables and $x^{2}$ test was employed for analysis of categorical variables. Significant variables in the univariate analysis were subjected to a multivariate logistic regression for determination of the independent significance of specific parameters. One-way ANOVA was used for comparisons of the means of more than two groups. Correlations between continuous variables were analyzed by Pearson's correlation coefficients. Survival curves were measured by the Kaplan-Meier method. Disease-specific survival was defined as the survival period between the diagnosis of the disease and the death of the patient due to disease recurrence after surgery. Log-rank test was used for comparison of survival between groups. Statistical analyses were performed using the SPSS computer statistical software (SPSS software; version 13.0; Chicago, IL, USA). A $P$ value of $<0.05$ was considered significant in each analysis.

\section{Results}

\section{Expression of apoptotic and anti-apoptotic proteins in} response to OPN in GIST cell lines

To assess the in vitro expression of apoptotic and antiapoptotic proteins in GIST, we treated the GIST882, sensitive to imatinib, and imatinib-resistant GIST48B and GIST62 GIST cell lines with OPN at different concentrations and analyzed the protein expression of specific apoptosis-related proteins by western blotting. In the anti-apoptotic proteins analyzed, we found increased expression of Mcl-1 and XIAP with correspondingly decreased expression of the apoptotic protein Bak, in response to OPN administration dose-dependently in GIST882. Knockdown of OPN in GIST882 cell lines showed inhibition of the anti-apoptotic effects of OPN demonstrated above (Figure 1). These data suggest a potential in vitro anti-apoptotic effect of OPN via upregulation of anti-apoptotic proteins in GIST882. Similar effects of OPN in promoting the expression of $\beta$-catenin and Mcl-1 were also noted in imatinib-resistant GIST48B and GIST62. In our previous studies, we identified that OPN may interact with CD44 to induce CD44 cleavage, possibly through increased expression of both $\beta$-catenin and cyclin D1 in GIST tumor tissues [17]. Western blotting using GIST882, GIST48B, and GIST62 cell lines in this study demonstrated compatible results. Dosedependent induction of CD44 cleavage and $\beta$-catenin expression in GIST cell lines upon OPN administration was observed regardless of drug-resistance (Figure 1).

\section{In vitro anti-apoptotic effects of OPN on imatinib-induced apoptosis in GIST}

Imatinib is an inhibitor of both normal and mutated KIT found in most GISTs and has been used for the treatment of patients with advanced GIST or for adjuvant therapy after surgical resection $[4,5]$. Imatinib has also been widely used to induce apoptosis in GIST882. We therefore used imatinib to further evaluate the antiapoptotic effects of OPN in GIST882, the known imatinibsensitive GIST cell line [28]. In the TUNEL assay for apoptosis analysis, GIST882 exhibited significant tumor cell apoptosis upon imatinib treatment in the absence of OPN, as expected. However, this pro-apoptotic effect of imatinib on GIST882 was significantly inhibited, or antagonized, upon OPN administration (Figure 2A,B), indicating an in vitro anti-apoptotic effect of OPN in GIST. We also analyzed the expression of apoptotic and antiapoptotic proteins by western blotting in the three groups of GIST882 cell lines used in the TUNEL assay and 


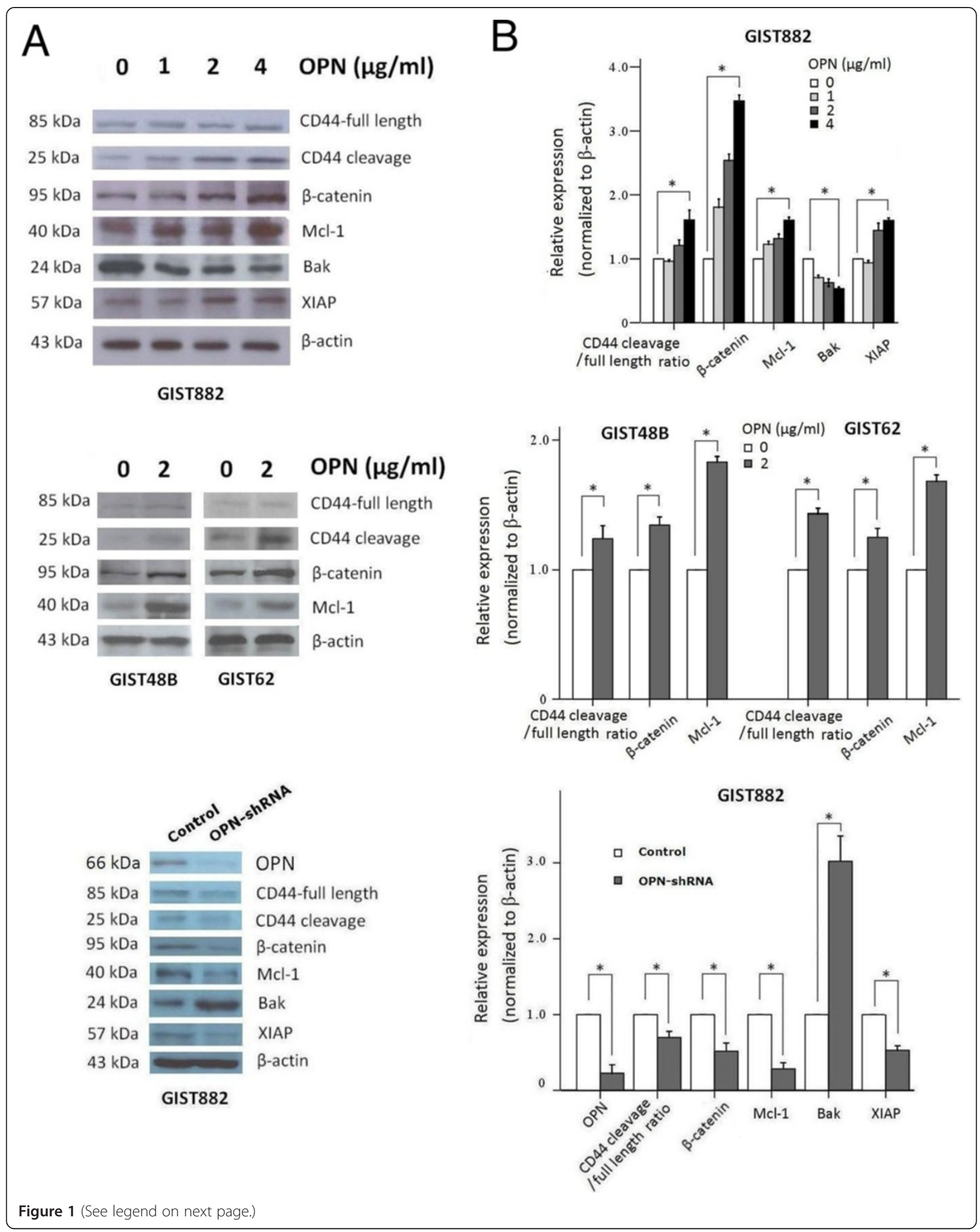



demonstrated in the lower panel. (B) Quantitation of the western blots by using $\beta$-actin as the control, demonstrating increased activities of the anti-apoptotic proteins, Mcl-1 and XIAP, with concomitant suppressed activities of apoptotic proteins Bak, after OPN administration in a dose-dependent manner in imatinib-sensitive GIST882. There were also increased activities of CD44 cleavage and $\beta$-catenin (upper). Similar effects of OPN in promoting the expression of $\beta$-catenin and Mcl-1 were also noted in imatinib-resistant GIST48B and GIST62 (Columns, mean of results in triplicate; bars, $\left.\mathrm{SD} .{ }^{*}, P<0.05\right)$.

found that significant changes in the expression level of $\beta$-catenin, Mcl-1, and XIAP were compatible with and corresponding to the results from the TUNEL assay (Figure 2C,D). Similarly, in imatinib-resistant GIST cell lines GIST48B and GIST62, significant upregulation of $\beta$-catenin and anti-apoptotic protein Mcl-1 in response to OPN was noted (Figure 3). Taken together, these findings suggest a significant anti-apoptotic effect of OPN against imatinib-induced apoptosis in GIST.

In conclusion, we suggest that OPN contributes to significant anti-apoptotic effects in GIST, against imatinibrelated apoptosis specifically, through the mechanism of up-regulation of $\beta$-catenin and anti-apoptotic protein Mcl-1, with concomitant suppression of apoptotic proteins.

\section{Significant correlation of $\beta$-catenin and anti-apoptotic protein $\mathrm{Mcl}-1$ expression in GIST}

In our previous investigations of the interaction of OPN and CD44 and the associated clinicopathologic significances in GIST, $\beta$-catenin was found likely to play an important role in the regulation of downstream signaling and functional effects subsequent to OPN and CD44 interaction [17]. In accordance with other series suggesting that OPN may be related to the induction of $\beta$-catenin or Wnt signaling pathways for regulating tumor progression, including resistance to apoptosis, in cancer cell lines [26,29-31], we confirmed that $\beta$-catenin can be a downstream effecter of OPN in GIST and may be regulating the expression of anti-apoptotic protein Mcl-1 (Figures 1-3). To further evaluate the association of $\beta$-catenin and Mcl-1, we analyzed the expression of both proteins in 31 patients with GIST by western blotting in the tumor specimens and normal counterpart tissues (Figure 4A). Having been normalized to $\beta$-actin for quantification of protein expression, both $\beta$-catenin and Mcl-1 exhibited tumor-specific overexpression, with significantly increased level of expression in tumor tissues relative to normal tissues $(P<0.001)$. The average protein expression levels of $\beta$-catenin and Mcl-1 were $0.42 \pm 0.25$ and $0.80 \pm 0.21$ (mean $\pm \mathrm{SD}$ ), respectively (Figure 4B). Additionally, we also analyzed the correlation between the expression levels of $\beta$-catenin and Mcl-1 and found that these two proteins showed significant positive correlations (Figure 4C). These results further support the close association between $\beta$-catenin and Mcl-1, as well as the significant regulatory role of $\beta$-catenin in GIST, as demonstrated in the western blotting analysis in GIST cell lines (Figures 1-3).

Clinicopathologic significance of Mcl-1 expression in GIST In GIST tumor specimens, increased expression of OPN and Mcl-1 can also be observed by immunohistochemical staining (Figure 4D). The expression and grading of OPN in GIST has been previously described [17]. To further evaluate the clinicopathologic significance of Mcl-1 expression in GIST, we use the mean tumor Mcl-1 expression value of 0.8 by western blotting as the cut-off level to define Mcl-1 activity in patients with GIST. Patients with Mcl-1 levels $\geq 0.8$ were those with strong Mcl-1 expression and others were those with weak Mcl-1 expression. Table 1 demonstrated the demographics and clinicopathological data in 31 patients with GIST with strong or weak Mcl-1 expression. No difference existed between the two groups in terms of age, gender, symptoms and signs, tumor size, mitotic figures, and recurrence. However, patients with strong Mcl-1 expression were significantly associated with a higher proportion of tumor localization at the stomach $(P=0.020)$ and strong OPN expression $(P=0.007)$. Subsequent multivariate analysis of these parameters revealed that only strong OPN expression remained the independent factor associated with increased Mcl-1 expression, indicating a significant and close correlation between OPN and Mcl-1 in GIST. These clinicopathologic data may also partly provide additional support to our previous in vitro findings that OPN contributes to significant anti-apoptotic effects in GIST through up-regulation of the anti-apoptotic protein Mcl-1. In the Kaplan-Meier estimation for overall and disease-specific survivals, patients with strong Mcl-1 expression showed worse overall and disease-specific survivals, compared with those with weak Mcl-1 expression ( $P=0.045$ and 0.042 , respectively) (Figure 5). These results revealed a prognostic value of Mcl-1 expression in patients with GIST.

\section{Discussion}

The anti-apoptotic role of OPN has been described in several human malignancies, including hepatocellular carcinoma (HCC), colorectal cancer, pancreatic cancer, 
A
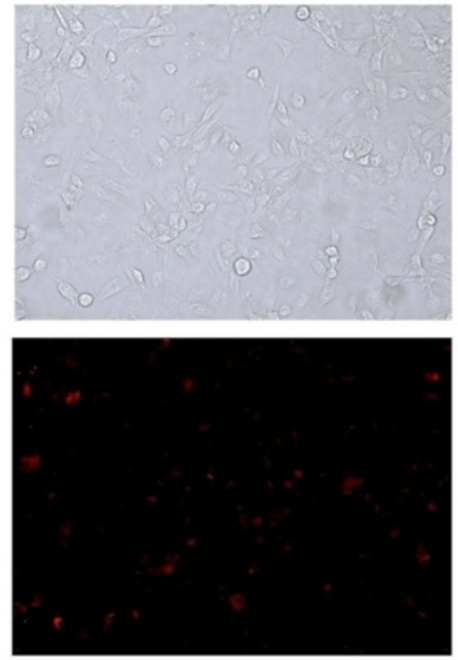

GIST882
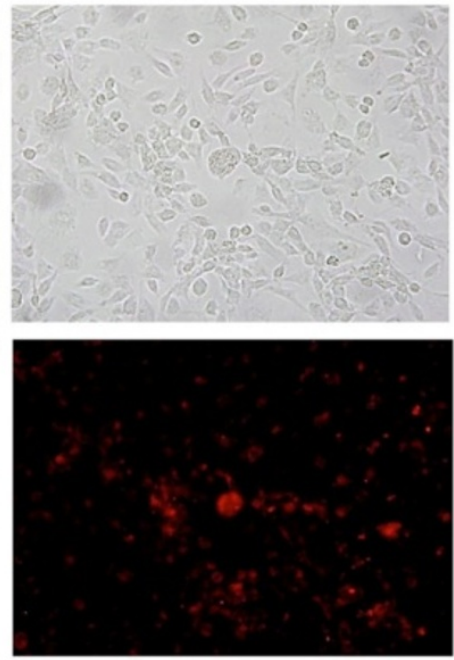

GIST882 + Imatinib
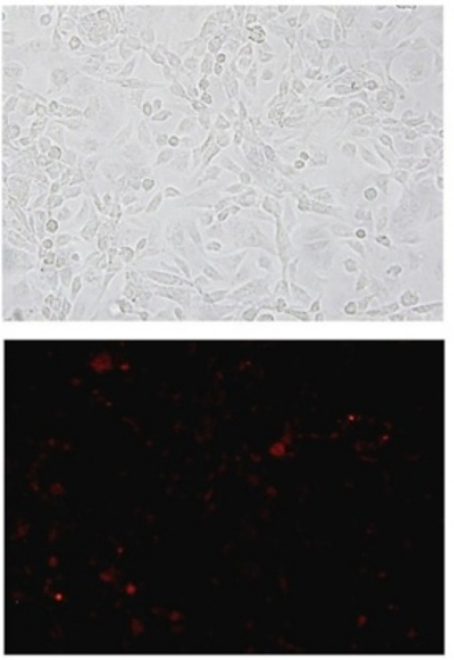

GIST882 + Imatinib + OPN
B

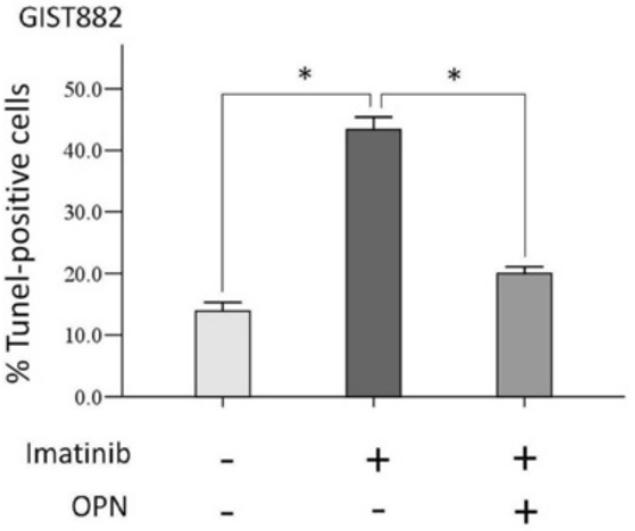

C

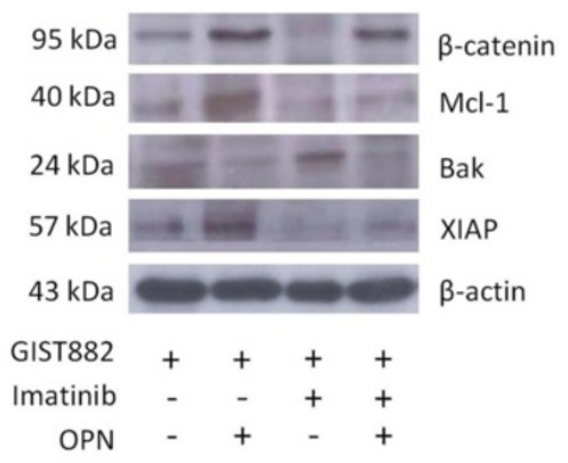

D
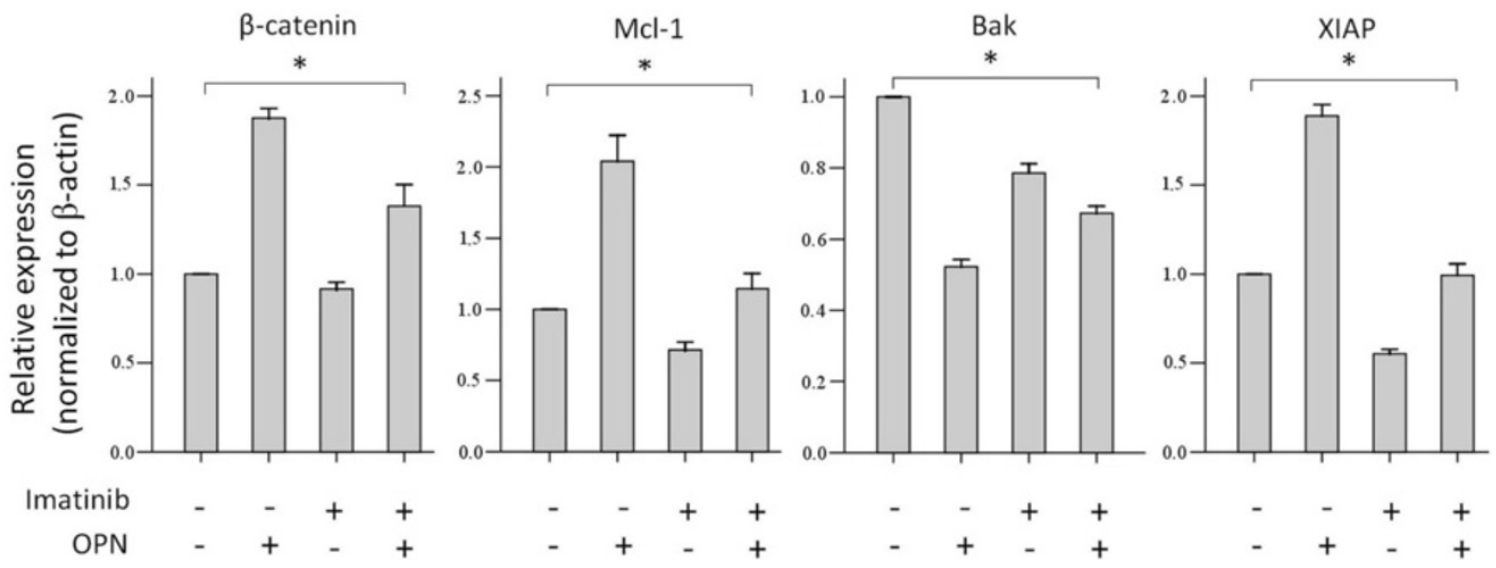

Figure 2 (See legend on next page.) 
(See figure on previous page.)

Figure 2 Antagonistic effect of OPN on imatinib-induced apoptosis in GIST882 by TUNEL assay. (A) Representative images indicating changes in the number of TUNEL-positive GIST882 tumor cells treated with imatinib $(1 \mu \mathrm{M})$ with or without OPN administration $(2 \mu \mathrm{g} / \mathrm{mL})$. (Original magnification: $\times 200$ ). (B) The number of TUNEL-positive tumor cells increased significantly in GIST882 treated with imatinib, whereas their numbers decreased significantly with simultaneous administration of OPN upon imatinib treatment, indicating an in vitro anti-apoptotic effect of OPN in GIST (Columns, mean of results in triplicate; bars, SD. *, $P<0.001$ ). (C) Western blotting analysis of GIST882 cell lines treated with imatinib and/or OPN, corresponding to the treatment used in the TUNEL assay. (D) Quantification of the western blots indicating that significant changes in the expression of anti-apoptotic and apoptotic proteins, in response to OPN in GIST882 cell lines treated with imatinib, were similar to changes in the percentage of apoptotic cells in the TUNEL assay (Columns, mean of results in triplicate; bars, SD. ${ }^{*}, P<0.05$, one-way ANOVA).

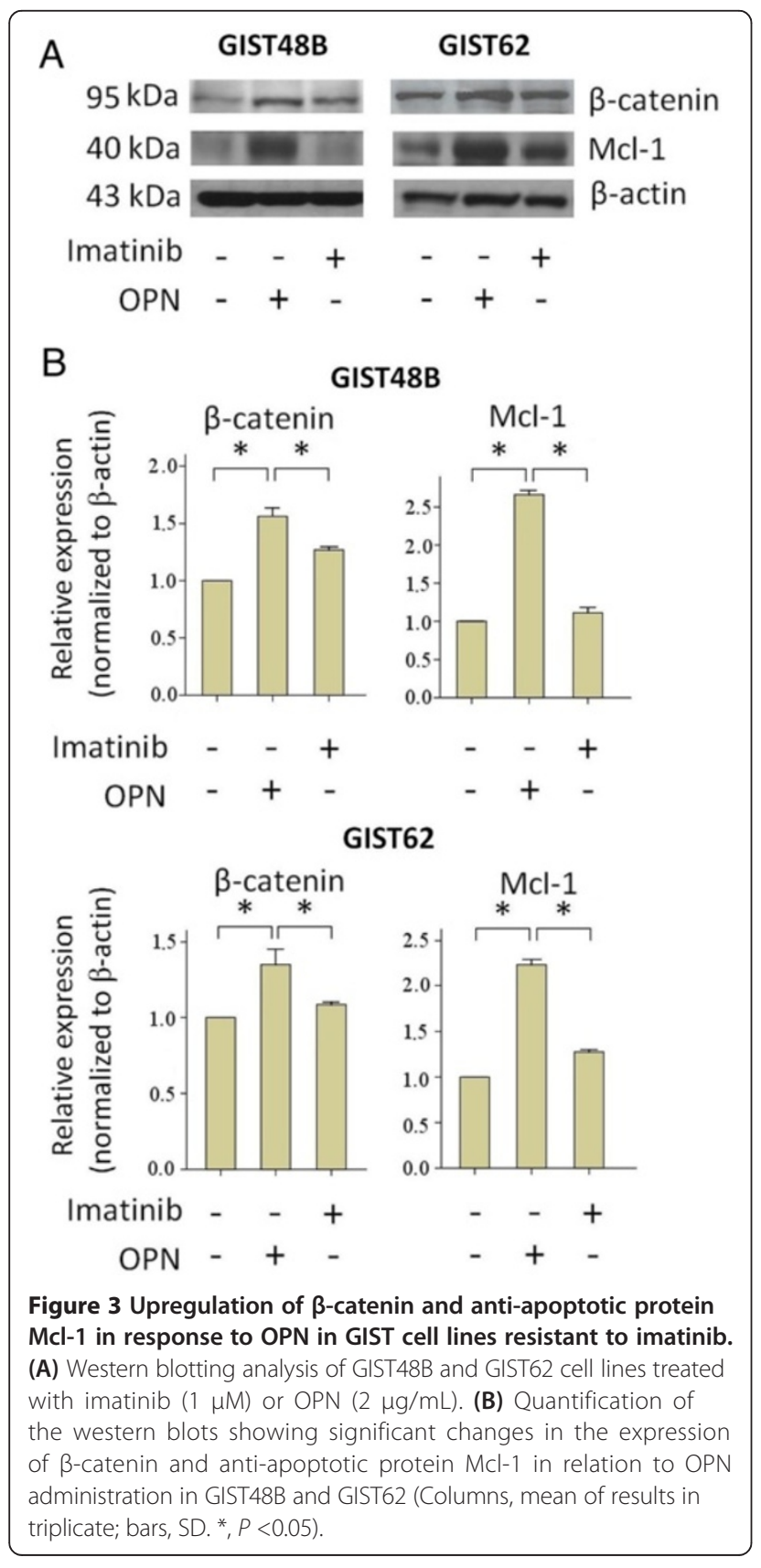

breast cancer, lung cancer, prostate cancer, and glioma [22-24]. In this study, we identified the anti-apoptotic effect of OPN in GIST for the first time. This antiapoptotic effect of OPN, through $\beta$-catenin-mediated upregulation of anti-apoptotic protein Mcl-1, was able to attenuate imatinib-induced apoptosis in GIST in vitro, suggesting a possible role of OPN and Mcl-1 in the mechanism underlying drug resistance to imatinib in GIST patients. The results from our study were similar to those of one report in which OPN was found to up-regulate the anti-apoptotic protein $\mathrm{Bcl}-2$ to cause inhibition of apoptosis, thus enhancing resistance to chemotherapy in lung cancer cell lines, indicating the involvement of OPN in the development of acquired chemoresistance [16]. One report also proposed that OPN, being a main anti-apoptotic factor that inhibited caspase 3-dependent apoptosis, was responsible for resistance to chemotherapy in a murine breast cancer cell line model [32]. Another study also identified that enhanced multidrug resistance in mesothelioma cells was induced and mediated through the anti-apoptotic effect of OPN [33]. In line with these studies, our finding that OPN exhibited significant anti-apoptotic effects in GIST, and specifically in the presence of imatinib, through anti-apoptotic protein Mcl-1 up-regulation, may be of value in supporting the rationale for development of new pharmaceutical strategies against imatinib-resistant GIST, which may be common in patients with disease recurrence or progression after imatinib treatment [6,7]. Our previous study has proved OPN overexpression to be associated with tumor recurrence in patients with resectable GIST [18]. Further studies are necessary to investigate the role of OPN expression in the particular GIST patient group undergoing neoadjuvant or adjuvant imatinib treatment that subsequently developed drug-resistance.

Some studies have focused on therapeutic agents or manipulations targeting apoptosis-related molecules in the treatment of GIST. Pharmaceutical molecules used to induce or promote apoptosis in GIST include Bortezomib, a dipeptide boronic acid inhibitor of the $20 \mathrm{~S}$ proteasome that, in part, impedes the degradation of pro-apoptotic 


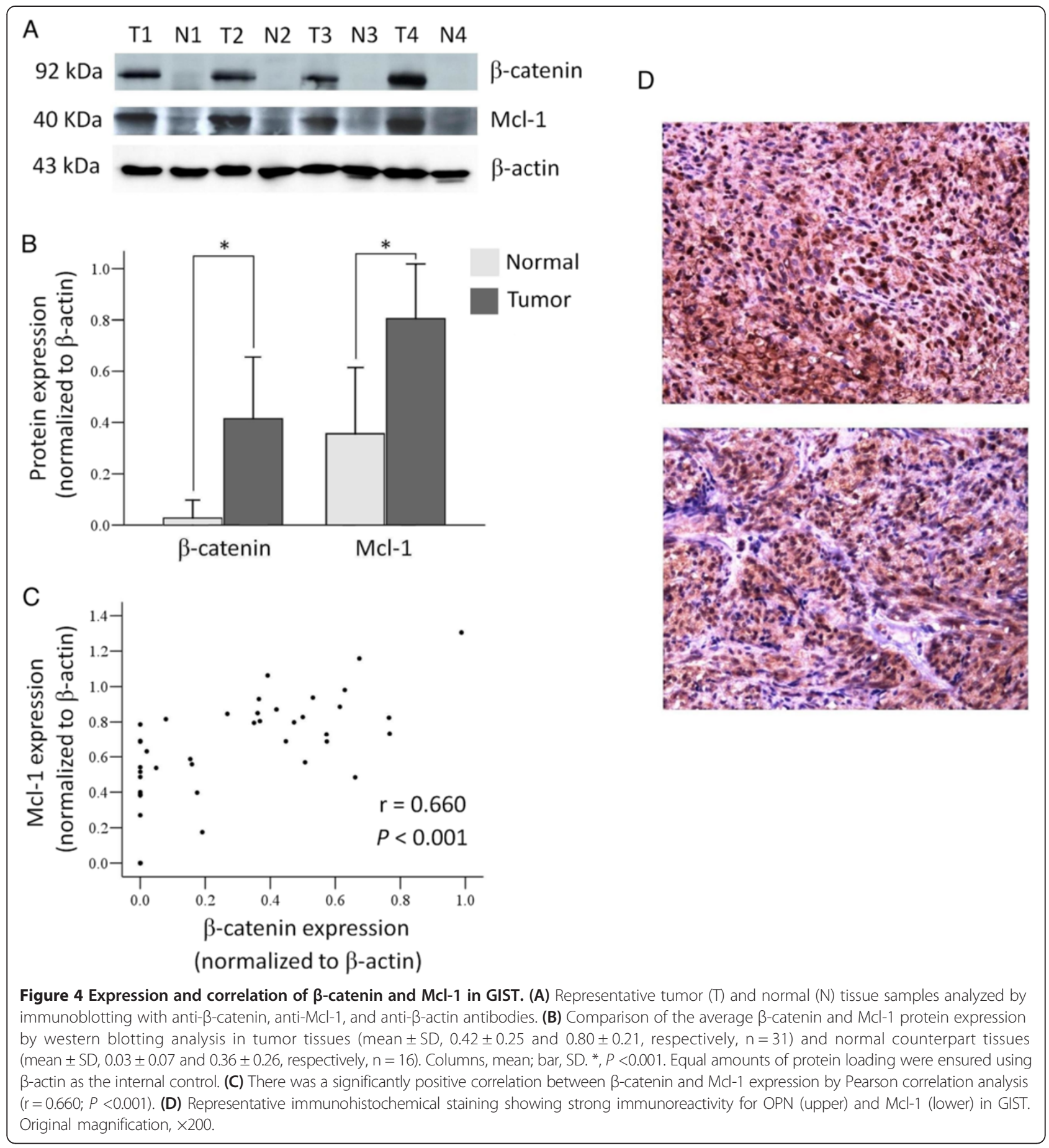

factors, thereby inducing apoptosis in neoplastic cells, and MegaFaL, a synthetic compound containing a hexameric form of soluble forms of Fas ligand (FasL; CD95L), which binds to Fas receptor for induction of Fas-mediated apoptosis $[34,35]$. One series also proposed that ABT-737, the pro-apoptotic Bcl-2/Bcl-xL inhibitor, can synergistically promote imatinib-induced cytotoxicity via apoptosis [36]. Our study suggests that OPN, with its igniting or initiating role of specific anti-apoptotic signaling transduction via up-regulation of anti-apoptotic protein Mcl-1 and its significant anti-apoptotic effect on inhibiting imatinib-induced apoptosis, may be a potential and promising target for pharmaceutical intervention in GIST resistant to conventional imatinib treatment. Along with our previous findings $[17,18]$, we identified the biologic significance of OPN in GIST to 
Table 1 Demographics and clinicopathological data in patients with GIST according to Mcl-1 expression

\begin{tabular}{|c|c|c|c|c|c|}
\hline & \multicolumn{2}{|l|}{ Mcl-1 expression } & \multirow{4}{*}{$\begin{array}{l}\text { Total No. of } \\
\text { patients (\%) }\end{array}$} & \multirow{4}{*}{$\begin{array}{l}\text { Univariate } \\
\text { analysis } \\
P \text { value * }\end{array}$} & \multirow{4}{*}{$\begin{array}{l}\text { Multivariate } \\
\text { analysis } \\
P \text { value }{ }^{*}\end{array}$} \\
\hline & Weak & Strong & & & \\
\hline & $<0.8$ & $\geq 0.8$ & & & \\
\hline & No. of patients (\%) & No. of patients (\%) & & & \\
\hline Number of patients & $15(48.4)$ & $16(51.6)$ & $31(100)$ & - & - \\
\hline Age (years), mean $\pm S D$ & $57.3 \pm 14.4$ & $63.2 \pm 11.8$ & $60.4 \pm 13.3$ & 0.225 & 0.505 \\
\hline \multicolumn{6}{|l|}{ Sex } \\
\hline Male & $7(46.7)$ & $8(50)$ & $15(48.4)$ & \multirow[t]{2}{*}{0.853} & \multirow[t]{2}{*}{0.465} \\
\hline Female & $8(53.3)$ & $8(50)$ & $16(51.6)$ & & \\
\hline \multicolumn{6}{|l|}{ Symptom and signs } \\
\hline Yes & $12(80)$ & $11(68.7)$ & $23(74.2)$ & \multirow[t]{2}{*}{0.474} & \\
\hline No & $3(20)$ & $5(31.3)$ & $8(25.8)$ & & \\
\hline \multicolumn{6}{|l|}{ Tumor location } \\
\hline Stomach & $5(33.3)$ & $12(75)$ & $17(54.8)$ & \multirow[t]{2}{*}{0.020} & \multirow[t]{7}{*}{0.051} \\
\hline Intestine & $10(66.7)$ & $4(25)$ & $14(45.2)$ & & \\
\hline Tumor size $(\mathrm{cm})$, mean $\pm \mathrm{SD}$ & $8.0 \pm 5.2$ & $7.4 \pm 4.5$ & $7.7 \pm 4.8$ & 0.745 & \\
\hline Mitosis (HPF), mean $\pm \mathrm{SD}$ & $20.3 \pm 22.9$ & $16.1 \pm 31.7$ & $18.1 \pm 27.4$ & 0.672 & \\
\hline \multicolumn{5}{|l|}{ Recurrence } & \\
\hline Yes & $5(33.3)$ & $4(25)$ & $9(29)$ & \multirow[t]{2}{*}{0.609} & \\
\hline No & $10(66.7)$ & $12(75)$ & $22(71)$ & & \\
\hline \multicolumn{6}{|l|}{ Osteopontin expression ${ }^{* *}$} \\
\hline Strong & $5(33.3)$ & $13(81.3)$ & 18 (58.1) & \multirow[t]{2}{*}{0.007} & \multirow[t]{2}{*}{0.015} \\
\hline Weak & $10(66.7)$ & $3(18.7)$ & 13 (41.9) & & \\
\hline
\end{tabular}

SD indicates standard deviation; HPF: high-power fields.

*Significant at the level of $P<0.05$.

** Strong: 3+; Weak: $<3+$

be associated with dual modes of actions, including proliferation-promoting as well as anti-apoptotic effects, indicating a pivotal role of OPN in tumor progression and malignant potential in GIST. These also provide evidence supporting OPN as an important target of pharmaceutical intervention in the treatment of GIST.

Mcl-1, a member of the anti-apoptotic Bcl-2 family, was originally cloned as an immediate-early induction gene expressed during differentiation of the ML-1 myeloid leukemia cells and functions as a regulator for survival and development in diverse cell types physiologically. In tumor biology, Mcl-1 plays an oncogenic role by maintaining tumor cell survival through its anti-apoptotic function [37,38]. Overexpression of Mcl-1 has been reported in a wide variety of human cancers, including gastrointestinal malignancies such as colorectal cancer, gastric cancer, and HCC [39-41]. Our study is the first to document Mcl-1 overexpression, its association with OPN anti-apoptotic effects, and its prognostic significance in predicting poor survival in GIST. We also identified a positive correlation in the expression of $\beta$-catenin and Mcl-1 in both GIST tumor specimens and
GIST cell lines, suggesting that $\beta$-catenin may be an effector of OPN-mediated up-regulation of Mcl-1 and anti-apoptosis in GIST. However, to further verify and conclude this putative mechanism of OPN-mediated upregulation of Mcl-1 through $\beta$-catenin in GIST proposed in our series, subsequent functional studies may be necessary. A similar regulatory role of OPN in $\beta$-catenin functions for anti-apoptosis has also been proposed in another study in which OPN was found to promote $\beta$-catenin signaling to induce resistance to apoptosis in prostate cancer cells [24].

It has been reported that Mcl-1 promotes cell survival by suppressing cytochrome $\mathrm{c}$ release from mitochondria through neutralization of pro-apoptotic proteins including Bak [42]. This is compatible with our finding that increased Mcl-1 expression was coupled with deceased expression of Bak, which may be part of the signaling pathway accounting for the anti-apoptotic function of Mcl-1 in response to OPN in GIST (Figure 1).

Mcl-1 has also been implicated as a key element in the resistance to conventional cancer therapies in certain human malignancies, including chronic myeloid leukemia, 


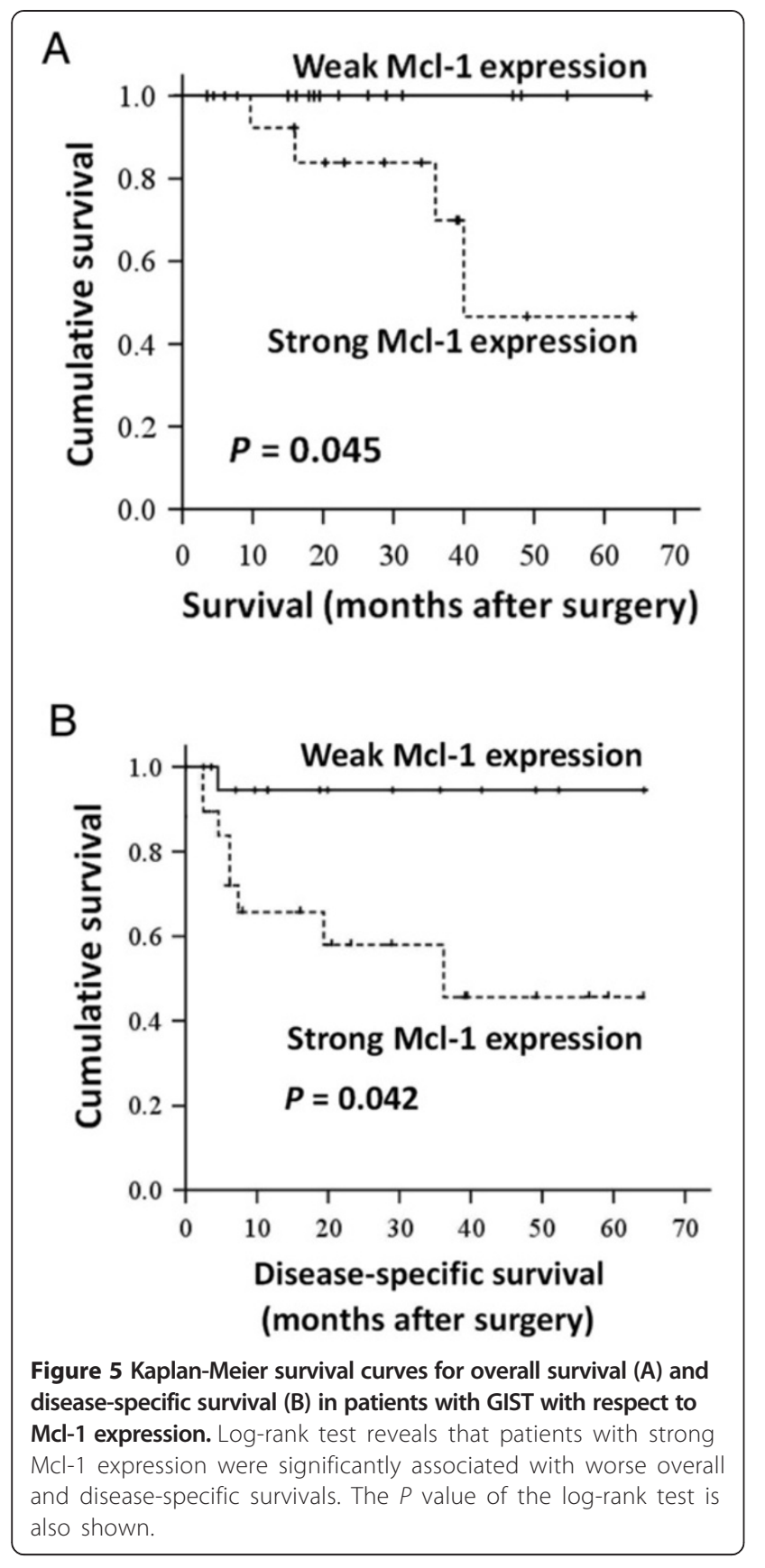

HCC, and cholangiocarcinoma [43-46]. The significance of Mcl-1 in its association with drug resistance and its overexpression in these human malignancies makes Mcl-1 a potential therapeutic target for intervention and treatment. However, though Mcl-1 overexpression in GIST was related to poor survival in this study, we have also noted the lack of association of strong Mcl-1 expression with mitotic rate, tumor size, and tumor location, three widely recognized and strongly validated prognostic parameters of GISTs. As revealed by the title of the study, the major finding of this study is the anti-apoptotic effects of OPN through up-regulation of Mcl-1 in GIST. Mcl-1, being an antiapoptotic protein, may be more likely to be an important mediator and participant in the signal pathways involved in the anti-apoptotic effects of OPN in GIST, rather than the different mechanisms regarding tumor proliferation and progression. It is therefore reasonable that the expression of the anti-apoptotic protein Mcl-1, is not directly associated with mitotic rate and tumor size, two major reliable indicators and poor prognostic factors for tumor proliferation, growth, and progression in GIST. According to our study, OPN, through up-regulation of anti-apoptotic protein Mcl-1, antagonized imatinibinduced apoptosis in GIST in vitro, suggesting a potential role of OPN and Mcl-1 in the mechanism underlying drug resistance to imatinib in GIST. As a result, Mcl-1 is more likely to be involved in the anti-apoptosis and drug resistance in GIST. This potential role of Mcl-1 in GIST drug-resistance merits further investigations. Our study also interestingly identified that strong Mcl-1 expression was associated with the favorable prognostic factor of gastric location in the univariate analysis, although this was only of borderline significance in the multivariate analysis $(P=0.051)$; the significance of this association is not clear. However, this is similar to another study in which CD133, being more significantly and more frequently expressed in gastric GIST (48\%) than in intestinal GIST (4\%), was also found to be a significant poor prognostic factor regarding overall survival in GIST [47]. It is notable that CD133, one of the well-recognized cancer stem cell markers in the GI tract, may potentially be involved in drug-resistance in GIST. This is also similar to the proposed role of Mcl-1 in the anti-apoptosis and drug-resistance in GIST in our study and awaits further investigation.

In this study, we found a significant association of OPN and increased Mcl-1 expression (Figure 1 and Table 1). We thus propose that OPN and Mcl-1 may be an upstream initiator and downstream effector, respectively, of the same anti-apoptotic signal pathway, in their contribution to resistance to imatinib-induced apoptosis in GIST. It is theoretically possible to simultaneously inhibit or target these two anti-apoptotic molecules on the same axis of survival signaling in order to obtain synergistic efficacy for induction of GIST tumor cell apoptosis. Interestingly, recent studies have identified that cyclooxygenase- 2 inhibitors can induce apoptosis and anti-tumor activities through down-regulation of OPN as well as Mcl-1 $[29,48,49]$. We therefore consider the use of cyclooxygenase-2 inhibitors for induction of apoptosis via down-regulation of dual targets of OPN and Mcl-1 as a promising strategy in the treatment of GIST, especially in imatinib-resistant GIST; further in vitro and in vivo studies are undergoing. 


\section{Conclusion}

In conclusion, we identified the anti-apoptotic effect of OPN in GIST for the first time. This anti-apoptotic effect of OPN, through $\beta$-catenin-mediated up-regulation of anti-apoptotic protein Mcl-1, also antagonized imatinibinduced apoptosis in GIST in vitro, suggesting a potential role of OPN and Mcl-1 in the mechanism underlying drug resistance to imatinib in GIST patients. Our results therefore provide evidence supporting the rationale for therapeutic strategies targeting both OPN and Mcl-1 to interrupt associated anti-apoptotic signaling in drugresistant GIST for prevention of tumor progression.

\section{Abbreviations}

GIST: Gastrointestinal stromal tumor; HCC: Hepatocellular carcinoma; OPN: Osteopontin; TUNEL: Terminal deoxynucleotidyl transferase-mediated dUTP nick end labeling.

\section{Competing interests}

The authors declare that they have no competing interests.

\section{Authors' contributions}

$\mathrm{KHH}$ carried out the conception and design of the study as well as acquisition and interpretation of the data. HWT and YSH contributed to the experiment and analyzed the data. PWL, PJL, and YSS made critical review of the manuscript. All authors read and approved the final version of the manuscript.

\section{Acknowledgements}

This study is supported by the National Science Council, Taiwan, Grant NSC-98-2314-B001-MY2; Department of Health Grant DOH99-TD-C-111-003.

\begin{abstract}
Author details
'Department of Surgery, Tainan Hospital, Ministry of Health and Welfare, Tainan 70428, Taiwan. ${ }^{2}$ Department of Surgery, National Cheng Kung University, College of Medicine, Tainan 70428, Taiwan. ${ }^{3}$ Institute of Clinical Medicine, National Cheng Kung University, College of Medicine, 138, Sheng-Li Road, Tainan 70428, Taiwan. ${ }^{4}$ Department of Pathology, National Cheng Kung University, College of Medicine, Tainan 70428, Taiwan. ${ }^{5}$ Department of Biotechnology, Southern Taiwan University of Technology, Tainan 70428, Taiwan.
\end{abstract}

Received: 18 February 2014 Accepted: 12 June 2014 Published: 20 June 2014

\section{References}

1. Hirota S, Isozaki K, Moriyama Y, Hashimoto K, Nishida T, Ishiguro S, Kawano K, Hanada M, Kurata A, Takeda M, Muhammad Tunio G, Matsuzawa Y, Kanakura Y, Shinomura Y, Kitamura Y: Gain-of-function mutations of c-KIT in human gastrointestinal stromal tumors. Science 1998, 279:577-580.

2. Fletcher CD, Berman JJ, Corless C, Gorstein F, Lasota J, Longley BJ, Miettinen M, O'Leary TJ, Remotti H, Rubin BP, Shmookler B, Sobin LH, Weiss SW: Diagnosis of gastrointestinal stromal tumors: a consensus approach. Hum Pathol 2002, 33:459-465.

3. Chi P, Chen Y, Zhang L, Guo X, Wongvipat J, Shamu T, Fletcher JA, Dewell S, Maki RG, Zheng D, Antonescu CR, Allis CD, Sawyers CL: ETV1 is a lineage survival factor that cooperates with KIT in gastrointestinal stromal tumours. Nature 2010, 467:849-853.

4. Demetri GD, von Mehren $M$, Blanke $C D$, Van den Abbeele AD, Eisenberg $B$, Roberts PJ, Heinrich MC, Tuveson DA, Singer S, Janicek M, Fletcher JA, Silverman SG, Silberman SL, Capdeville R, Kiese B, Peng B, Dimitrijevic S, Druker BJ, Corless C, Fletcher CD, Joensuu H: Efficacy and safety of imatinib mesylate in advanced gastrointestinal stromal tumors. $N$ Engl $J$ Med 2002, 347:472-480.

5. Dematteo RP, Ballman KV, Antonescu CR, Maki RG, Pisters PW, Demetri GD, Blackstein ME, Blanke CD, von Mehren M, Brennan MF, Patel S, McCarter MD, Polikoff JA, Tan BR, Owzar K, American College of Surgeons Oncology Group (ACOSOG) Intergroup Adjuvant GIST Study Team: Adjuvant imatinib mesylate after resection of localised, primary gastrointestinal stromal tumour: a randomised, double-blind, placebo-controlled trial. Lancet 2009, 373:1097-1104.

6. Verweij J, Casali PG, Zalcberg J, LeCesne A, Reichardt P, Blay JY, Issels R, van Oosterom A, Hogendoorn PC, Van Glabbeke M, Bertulli R, Judson I: Progression-free survival in gastrointestinal stromal tumours with high-dose imatinib: randomised trial. Lancet 2004, 364:1127-1134.

7. Corless $C L$, Fletcher JA, Heinrich MC: Biology of gastrointestinal stromal tumors. J Clin Oncol 2004, 22:3813-3825.

8. Senger DR, Wirth DF, Hynes RO: Transformed mammalian cells secrete specific proteins and phosphoproteins. Cell 1979, 16:885-893.

9. Weber GF, Ashkar S, Glimcher MJ, Cantor H: Receptor-ligand interaction between CD44 and osteopontin (Eta-1). Science 1996, 271:509-512.

10. Denhardt DT, Noda M, O'Regan AW, Pavlin D, Berman JS: Osteopontin as a means to cope with environmental insults: regulation of inflammation, tissue remodeling, and cell survival. J Clin Invest 2001, 107:1055-1061.

11. Rangaswami H, Bulbule A, Kundu GC: Osteopontin: role in cell signaling and cancer progression. Trends Cell Biol 2006, 16:79-87.

12. Coppola D, Szabo M, Boulware D, Muraca P, Alsarraj M, Chambers AF, Yeatman TJ: Correlation of osteopontin protein expression and pathological stage across a wide variety of tumor histologies. Clin Cancer Res 2004, 10:184-190.

13. Rittling SR, Chambers AF: Role of osteopontin in tumour progression. $\mathrm{Br} J$ Cancer 2004, 90:1877-1881.

14. Zhao J, Dong L, Lu B, Wu G, Xu D, Chen J, Li K, Tong X, Dai J, Yao S, Wu M, Guo Y: Down-regulation of osteopontin suppresses growth and metastasis of hepatocellular carcinoma via induction of apoptosis. Gastroenterology 2008, 135:956-968.

15. Blasberg JD, Pass HI, Goparaju CM, Flores RM, Lee S, Donington JS: Reduction of elevated plasma osteopontin levels with resection of non-small-cell lung cancer. J Clin Oncol 2010, 28:936-941.

16. Wu CY, Wu MS, Chiang EP, Wu CC, Chen YJ, Chen CJ, Chi NH, Chen GH, Lin JT: Elevated plasma osteopontin associated with gastric cancer development, invasion and survival. Gut 2007, 56:782-789.

17. Hsu KH, Tsai HW, Lin PW, Hsu YS, Shan YS, Lu PJ: Clinical implication and mitotic effect of CD44 cleavage in relation to osteopontin/CD44 interaction and dysregulated cell cycle protein in gastrointestinal stromal tumor. Ann Surg Oncol 2010, 17:2199-2212.

18. Hsu KH, Tsai HW, Lin PW, Hsu YS, Shan YS, Lu PJ: Osteopontin expression is an independent adverse prognostic factor in resectable gastrointestinal stromal tumor and its interaction with CD44 promotes tumor proliferation. Ann Surg Oncol 2010, 17:3043-3052.

19. Weber GF, Ashkar S, Cantor H: Interaction between CD44 and osteopontin as a potential basis for metastasis formation. Proc Assoc Am Physicians 1997, 109:1-9.

20. Burdo TH, Wood MR, Fox HS: Osteopontin prevents monocyte recirculation and apoptosis. J Leukoc Biol 2007, 81:1504-1511.

21. Hao Y, Murphy CN, Spate L, Wax D, Zhong Z, Samuel M, Mathialagan N, Schatten H, Prather RS: Osteopontin improves in vitro development of porcine embryos and decreases apoptosis. Mol Reprod Dev 2008, 75:291-298.

22. Huang $H$, Zhang XF, Zhou HJ, Xue $Y H$, Dong QZ, Ye QH, Qin LX: Expression and prognostic significance of osteopontin and caspase-3 in hepatocellular carcinoma patients after curative resection. Cancer Sci 2010, 101:1314-1319.

23. Valcz G, Sipos F, Krenács T, Molnár J, Patai AV, Leiszter K, Tóth $\mathrm{K}$, Solymosi $\mathrm{N}$, Galamb O, Molnár B, Tulassay Z: Elevated osteopontin expression and proliferative/apoptotic ratio in the colorectal adenoma-dysplasiacarcinoma sequence. Pathol Oncol Res 2010, 16:541-545.

24. Robertson BW, Chellaiah MA: Osteopontin induces beta-catenin signaling through activation of Akt in prostate cancer cells. Exp Cell Res 2010, 316:1-11.

25. Zhang H, Guo M, Chen JH, Wang Z, Du XF, Liu PX, Li WH: Osteopontin knockdown inhibits av, $\beta 3$ integrin-induced cell migration and invasion and promotes apoptosis of breast cancer cells by inducing autophagy and inactivating the PI3K/Akt/mTOR pathway. Cell Physiol Biochem 2014, 33:991-1002.

26. Zhang A, Liu Y, Shen Y, Xu Y, Li X: Osteopontin silencing by small interfering RNA induces apoptosis and suppresses invasion in human renal carcinoma Caki-1 cells. Med Oncol 2010, 27:1179-1184. 
27. Hsu KH, Tsai HW, Shan YS, Lin PW: Significance of CD44 expression in gastrointestinal stromal tumors in relation to disease progression and survival. World J Surg 2007, 31:1438-1444.

28. Bauer S, Duensing A, Demetri GD, Fletcher JA: KIT oncogenic signaling mechanisms in imatinib-resistant gastrointestinal stromal tumor: PI3kinase/AKT is a crucial survival pathway. Oncogene 2007, 26:7560-7568.

29. Zagani R, Hamzaoui N, Cacheux W, de Reyniès A, Terris B, Chaussade S, Romagnolo B, Perret C, Lamarque D: Cyclooxygenase-2 inhibitors downregulate osteopontin and $\mathrm{Nr} 4 \mathrm{~A} 2$-new therapeutic targets for colorectal cancers. Gastroenterology 2009, 137:1358-1366.

30. Mason CK, McFarlane S, Johnston PG, Crowe P, Erwin PJ, Domostoj MM, Campbell FC, Manaviazar S, Hale KJ, El-Tanani M, Agelastatin A: Agelastatin A: a novel inhibitor of osteopontin-mediated adhesion, invasion, and colony formation. Mol Cancer Ther 2008, 7:548-558.

31. Gu T, Ohashi R, Cui R, Tajima K, Yoshioka M, Iwakami S, Sasaki S, Shinohara A, Matsukawa T, Kobayashi J, Inaba Y, Takahashi K: Osteopontin is involved in the development of acquired chemo-resistance of cisplatin in small cell lung cancer. Lung Cancer 2009, 66:176-183.

32. Graessmann M, Berg B, Fuchs B, Klein A, Graessmann A: Chemotherapy resistance of mouse WAP-SVT/t breast cancer cells is mediated by osteopontin, inhibiting apoptosis downstream of caspase-3. Oncogene 2007, 26:2840-2850

33. Tajima K, Ohashi R, Sekido Y, Hida T, Nara T, Hashimoto M, Iwakami S, Minakata K, Yae T, Takahashi F, Saya H, Takahashi K: Osteopontin-mediated enhanced hyaluronan binding induces multidrug resistance in mesothelioma cells. Oncogene 2010, 29:1941-1951.

34. Bauer $S$, Parry JA, Mühlenberg T, Brown MF, Seneviratne $D$, Chatterjee $P$, Chin A, Rubin BP, Kuan SF, Fletcher JA, Duensing S, Duensing A: Proapoptotic activity of bortezomib in gastrointestinal stromal tumor cells. Cancer Res 2010, 70:150-159.

35. Rikhof B, van der Graaf WT, Meijer C, Le PT, Meersma GJ, de Jong S, Fletcher $J A$, Suurmeijer AJ: Abundant Fas expression by gastrointestinal stromal tumours may serve as a therapeutic target for MegaFasL. Br J Cancer 2008, 99:1600-1606.

36. Reynoso D, Nolden LK, Yang D, Dumont SN, Conley AP, Dumont AG, Zhou K, Duensing A, Trent JC: Synergistic induction of apoptosis by the BCl-2 inhibitor ABT-737 and imatinib mesylate in gastrointestinal stromal tumor cells. Mol Oncol 2011, 5:93-104

37. Vaux DL, Cory S, Adams JM: Bcl-2 gene promotes haemopoietic cell survival and cooperates with c-myc to immortalize pre-B cells. Nature 1988, 335:440-442

38. Thomas LW, Lam C, Edwards SW: Mcl-1; the molecular regulation of protein function. FEBS Lett 2010, 584:2981-2989.

39. Backus HH, van Riel JM, van Groeningen CJ, Vos W, Dukers DF, Bloemena E, Wouters D, Pinedo HM, Peters GJ: Rb, mcl-1 and $\mathrm{p} 53$ expression correlate with clinical outcome in patients with liver metastases from colorectal cancer. Ann Oncol 2001, 12:779-785.

40. Likui W, Qun L, Wanqing Z, Haifeng S, Fangqiu L, Xiaojun L: Prognostic role of myeloid cell leukemia-1 protein (Mcl-1) expression in human gastric cancer. J Surg Oncol 2009, 100:396-400.

41. Sieghart W, Losert D, Strommer S, Cejka D, Schmid K, Rasoul-Rockenschaub S, Bodingbauer M, Crevenna R, Monia BP, Peck-Radosavljevic M, Wacheck V: Mcl-1 overexpression in hepatocellular carcinoma: A potential target for antisense therapy. J Hepatol 2006, 44:151-157.

42. Shimazu T, Degenhardt K, Nur-E-Kamal A, Zhang J, Yoshida T, Zhang Y, Mathew R, White E, Inouye M: NBK/BIK antagonizes MCL-1 and BCL-XL and activates BAK-mediated apoptosis in response to protein synthesis inhibition. Genes Dev 2007, 21:929-941.

43. Balakrishnan K, Burger JA, Wierda WG, Gandhi V: AT-101 induces apoptosis in CLL B cells and overcomes stromal cell-mediated Mcl-1 induction and drug resistance. Blood 2009, 113:149-153.

44. Campbell KJ, Bath ML, Turner ML, Vandenberg CJ, Bouillet P, Metcalf $D$ Scott CL, Cory S: Elevated Mcl-1 perturbs lymphopoiesis, promotes transformation of hematopoietic stem/progenitor cells and enhances drug-resistance. Blood 2010, 116:3197-3207.

45. Okaro AC, Fennell DA, Corbo M, Davidson BR, Cotter FE: Pk11195, a mitochondrial benzodiazepine receptor antagonist, reduces apoptosis threshold in $\mathrm{BCl}-\mathrm{X}(\mathrm{L})$ and $\mathrm{Mcl}-1$ expressing human cholangiocarcinoma cells. Gut 2002, 51:556-561.

46. Kobayashi S, Werneburg NW, Bronk SF, Kaufmann SH, Gores GJ: Interleukin-6 contributes to Mcl-1 up-regulation and TRAIL resistance via an Akt- signaling pathway in cholangiocarcinoma cells. Gastroenterology 2005, 128:2054-2065.

47. Arne G, Kristiansson E, Nerman O, Kindblom LG, Ahlman H, Nilsson B, Nilsson O: Expression profiling of GIST: CD133 is associated with KIT exon 11 mutations, gastric location and poor prognosis. Int $J$ Cancer 2011, 129:1149-1161.

48. Kern MA, Haugg AM, Koch AF, Schilling T, Breuhahn K, Walczak H, Fleischer B, Trautwein C, Michalski C, Schulze-Bergkamen H, Friess H, Stremmel W, Krammer PH, Schirmacher P, Müller M: Cyclooxygenase-2 inhibition induces apoptosis signaling via death receptors and mitochondria in hepatocellular carcinoma. Cancer Res 2006, 66:7059-7066.

49. Rudner J, Elsaesser SJ, Müller AC, Belka C, Jendrossek V: Differential effects of anti-apoptotic BCl-2 family members $\mathrm{MCl}-1, \mathrm{BCl}-2$, and $\mathrm{BCl}-\mathrm{xL}$ on celecoxib-induced apoptosis. Biochem Pharmacol 2010, 79:10-20.

doi:10.1186/1477-7819-12-189

Cite this article as: Hsu et al:: Anti-apoptotic effects of osteopontin through the up-regulation of $\mathrm{Mcl}-1$ in gastrointestinal stromal tumors. World Journal of Surgical Oncology 2014 12:189.

\section{Submit your next manuscript to BioMed Central and take full advantage of:}

- Convenient online submission

- Thorough peer review

- No space constraints or color figure charges

- Immediate publication on acceptance

- Inclusion in PubMed, CAS, Scopus and Google Scholar

- Research which is freely available for redistribution

Submit your manuscript at www.biomedcentral.com/submit
() Biomed Central 